\title{
Avaliação espectrofotométrica do azul de Evans na reação inflamatória da córnea: estudo experimental em coelhos
}

\author{
Spectrophotometric evaluation of Evans blue in inflammatory cornea reaction: \\ experimental study in rabbits
}

\author{
Marcelo Luiz Gehlen ${ }^{1}$ \\ Hamilton Moreira ${ }^{2}$ \\ Luciane Moreira ${ }^{3}$ \\ Fábio Prado Sabag 4 \\ João Carlos Doming'ues Repka ${ }^{5}$
}

Faculdade Evangélica do Paraná - Curitiba (PR)

${ }^{1}$ Preceptor do serviço de Oftalmologia do Hospital Universitário Evangélico de Curitiba; Professor Assistente de Oftalmologia da Faculdade Evangélica do Paraná; Professor colaborador de Oftalmologia da Universidade Federal do Paraná.

${ }^{2}$ Preceptor do Serviço de Oftalmologia do Hospital Universitário Evangélico de Curitiba; Professor Titular de Oftalmologia da Faculdade Evangélica do Paraná; Professor adjunto de Oftalmologia da Universidade Federal do Paraná.

${ }_{3}^{3}$ Preceptora do serviço de Oftalmologia do Hospital Universitário Evangélico de Curitiba e Professora Colaboradora de Oftalmologia da Faculdade Evangélica do Paraná.

${ }^{4}$ Oftalmologista do Hospital Vita - Curitiba.

Professor Titular de Imunologia e Microbiologia da Faculdade Evangélica do Paraná; Preceptor de Imunologia e Microbiologia do Hospital Angelina Caron; Professor de Imunologia e Microbiologia da Pontifícia Universidade Católica do Paraná.

Endereço para correspondência: MarceloLuiz Gehlen Al. Princesa Isabel, 1464/84 - Curitiba (PR) CEP 80730-080 E-mail: smgehlen@terra.com.br

Recebido para publicação em 01.03.2002

Versão revisada recebida em 14.02.2003

Aprovação em 30.11.2003

\section{RESUMO}

Objetivo: Constatar a presença do azul de Evans na córnea normal estipulando o período de tempo de concentração máxima do corante após inoculação endovenosa e estudar a permeabilidade vascular em modelo animal da inflamação corneal induzida por queimadura química por meio de injeção de azul de Evans. Métodos: Cinquenta coelhos foram divididos em 3 grupos: Grupo I (25 animais): injetou-se $20 \mathrm{mg} / \mathrm{kg}$ de azul de Evans e os animais foram sacrificados após 8, 10, 12, 14 e 16 horas. Retirou-se a córnea e quantificou-se o corante por meio de micrométodo espectrofotométrico. Grupo II: em 15 animais injetou-se o corante e, após 10 horas, fragmentouse centralmente o tecido com trépanos de 6, 8 e $10 \mathrm{~mm}$. Procedeu-se à extração do azul de Evans da mesma forma que no grupo I. Grupo III: induziu-se queimadura na córnea do olho direito de 10 animais com $\mathrm{NaOHa} 1 \mathrm{~N}$. Cinco dias após o procedimento, os animais foram sacrificados, sendo que, 10 horas antes do sacrifício, foi inoculado o azul de Evans para que posteriormente se pudesse quantificá-lo. A córnea esquerda serviu como controle. Resultados: No grupo I, a média da concentração do azul de Evans às $10 \mathrm{~h}$. foi de $15,28 \pm 0,09 \mu \mathrm{g} / \mathrm{mg}$. No grupo II, as médias das concentrações do corante foram: $6 \mathrm{~mm}: 0,93 \pm 0,01 \mu \mathrm{g} / \mathrm{mg} ; 8 \mathrm{~mm}: 1,20 \pm 0,06 \mu \mathrm{g} / \mathrm{mg} ; 10 \mathrm{~mm}: 1,32$ $\pm 0,05 \mu \mathrm{g} / \mathrm{mg}$. No grupo III, as médias das concentrações do azul de Evans foram: olho direito (queimadura): 23,74 $\pm 2,64 \mu \mathrm{g} / \mathrm{mg}$ e olho esquerdo (controle): 16,71 $\pm 2,04 \mu \mathrm{g} / \mathrm{mg}$. Conclusões: Quantificou-se o azul de Evans pela primeira vez na córnea de coelhos e constatou-se que, após 10 horas de inoculação endovenosa, o corante atingiu seu pico de concentração no tecido. Concluiu-se que o azul de Evans serve como bom método de quantificação da permeabilidade vascular alterada na córnea de coelhos.

Descritores: Azul de Evans, espectrofotometria; Permeabilidade; Córnea; Coelhos

\section{INTRODUÇ̃̃̃O}

Desde 1943, com os primeiros estudos de Rawson, o azul de Evans tem sido amplamente utilizado em diversos trabalhos experimentais. Este corante apresenta algumas características como inocuidade ${ }^{(1-2)}$, alta solubilidade em água e afinidade pela albumina ${ }^{(3-5)}$. O azul de Evans, quando inoculado via endovenosa, combina-se com a albumina de maneira reversível e dependente de $\mathrm{pH}^{(4)}$.

Estudos demonstraram que, após 40 horas da administração endovenosa do azul de Evans em ratos, $90 \%$ do corante já havia deixado a circulação, atingindo diversos tecidos do organismo. Depois de 24 horas de inoculação 
endovenosa, $30 \%$ do corante foi encontrado na pele, $13 \%$ nos músculos, $12 \%$ no fígado e $9 \%$ nos $\operatorname{ossos}^{(6-7)}$.

A inflamação aguda provoca alterações no fluxo sangüíneo, no calibre dos vasos e na permeabilidade vascular. O exsudato produzido quando existe alteração da permeabilidade vascular contém mais proteínas plasmáticas do que em situação normal ${ }^{(8)}$. O azul de Evans se combina à albumina plasmática formando um complexo corante-albumina que extravasa através da barreira endotelial lesada ${ }^{(9)}$.

Autores revelaram que, ao promover-se uma reação inflamatória, o aumento do exsudato plasmático para um tecido lesado eleva as taxas de azul de Evans neste tecido ${ }^{(2,10-14)}$.

Existem técnicas de mensuração da permeabilidade vascular em tecidos como dosagem de catabólitos do ácido araquidônico ${ }^{(15-17)}$, quantificação do conteúdo aquoso, mensuração do escape de albumina marcado com iodo radioativo e marcação vascular com carbono coloidal, sendo que estas técnicas requerem considerável implementação laboratorial (18-19). Há outros corantes, além do azul de Evans, que se ligam à albumina, como o azul Celeste de Niágara, o azul Celeste de Pontamina 6BX e o azul de Tripan ${ }^{(2,10-14,20-29)}$. O azul de Evans é um corante capaz de ser mensurável por meio de espectrofotometria ${ }^{(11-12)}$.

Há vários modelos experimentais de inflamação aguda induzida na córnea. A queimadura química por álcali produz lesão grave ao olho com edema importante, desepitelização e neovascularização ${ }^{(30-36)}$.

Reações inflamatórias induzidas pelo ácido acético a $10 \%$ em intestino correlacionam-se com incremento da permeabilidade vascular quantificado pelo azul de Evans. As determinações das concentrações do corante foram realizadas pelo micrométodo espectrofotométrico que requer baixo custo quando comparado a outros modos de quantificação da inflamação aguda ${ }^{(11-12)}$.

Revisando-se a literatura, encontrou-se relatos de avaliação do fluxo transcapilar evidenciado através do azul de Evans em diversos tecidos, tais como pele, coração e cólon ${ }^{(11-12,37)}$. Não há relatos desta metodologia no tecido corneano.

\section{OBJETIVOS}

Os objetivos deste estudo foram:

- Verificar o período de tempo de concentração máxima do azul de Evans na córnea de coelhos após inoculação endovenosa.

- Avaliar o mecanismo de difusão do corante no tecido corneano.

- Estudar a permeabilidade vascular em modelo animal de inflamação corneal induzida por queimadura química corneana através da injeção de azul de Evans.

\section{MÉTODOS}

\section{Delineamento experimental}

O presente estudo foi realizado no laboratório de Microbiologia e Imunologia da Faculdade Evangélica do Paraná.
Adotaram-se as Normas de Apresentação de Trabalhos da Universidade Federal do Paraná (2000), normas para referências bibliográficas de títulos e periódicos da Associação Brasileira de Normas Técnicas (NBR-6023) (1989), Nomina Anatômica Veterinária (1983) bem como os Princípios Éticos na Experimentação Animal propostos pelo Colégio Brasileiro de Experimentação Animal (1994).

\section{Amostra}

Foram utilizados 50 coelhos (Oryctolagus cuniculus) albinos machos de aproximadamente $1.500 \mathrm{~g}$ provenientes do Instituto de Tecnologia do Paraná - TECPAR.

Os animais foram colocados em alojamentos apropriados e divididos em três grupos que receberam água e ração específica para a espécie.

\subsection{Preparo da amostra}

\subsubsection{Procedimento anestésico}

O procedimento anestésico foi realizado para inoculação do corante, para o procedimento de queimadura corneana e para o sacrifício de todos os animais do experimento. Utilizouse um funil de plástico com algodão embebido em éter sulfúrico. O funil era então colocado nas vias externas aéreas do coelho até o relaxamento muscular e anestesia do mesmo. Somente no grupo III foi utilizada anestesia tópica com colírio de cloridrato de proximetacaína $0,5 \%$ previamente à queimadura da córnea.

\subsubsection{Grupo I}

Primeiramente 25 animais foram utilizados para a determinação do período de tempo ideal no qual houvesse concentração máxima do corante na córnea. Nesta etapa, sacrificaram-se cinco animais a partir das primeiras oito horas após inoculação do azul de Evans para coleta de dez córneas. Da mesma forma, conduziu-se à coleta dos tecidos após 10, 12, 14 e 16 horas pós-injeção do corante. Para coleta das amostras, retirou-se a córnea com $1 \mathrm{~mm}$ de margem escleral.

\subsubsection{Grupo II}

Na segunda etapa do trabalho, 15 animais foram subdivididos em três subgrupos de 5 animais (10 amostras de tecido corneano) para verificação do mecanismo de difusão do corante na córnea normal. Dez horas após inoculação do corante azul de Evans houve o sacrifício dos animais e coleta dos tecidos corneanos com $1 \mathrm{~mm}$ de margem escleral. Imediatamente as amostras foram submetidas a uma trepanação. No primeiro subgrupo a trepanação atingiu somente os $6 \mathrm{~mm}$ centrais da córnea; segundo $8 \mathrm{~mm}$ e no terceiro $10 \mathrm{~mm}$ de trepanação do tecido ocular. Os trépanos usados foram os mesmos para todos os animais, manuseados por um mesmo cirurgião e tendo-se o cuidado de trepanar a porção central da córnea.

\subsubsection{Grupo III}

Na última etapa da pesquisa, 10 animais foram submetidos 
à queimadura corneana do olho direito com hidróxido de sódio a $1 \mathrm{~N}(\mathrm{NaOH})$. $\mathrm{O}$ olho esquerdo manteve-se como controle. $\mathrm{O}$ material absorvente (papel filtro) de $15 \mathrm{~mm}$ de diâmetro foi embebido por 20 segundos em solução de hidróxido de sódio a $1 \mathrm{~N}$ e aplicado sobre a córnea direita durante 45 segundos. Após este período de tempo retirou-se o papel filtro e irrigouse a córnea com $20 \mathrm{ml}$ de soro fisiológico a $0,9 \%$. Os animais ficaram num alojamento apropriado por 5 dias para que posteriormente houvesse o sacrifício (Figura 1). Dez horas antes deste procedimento, foi inoculado o azul de Evans. Obteve-se vinte amostras dos dez animais componentes deste grupo.

\section{Organização do método}

\subsection{Preparo das soluções e reagentes}

\subsubsection{Solução do azul de Evans}

Foi preparada uma solução de azul de Evans a 2,5\%, MERCK $^{\circledast}$ artigo 3169 , em solução fisiológica, num volume suficiente para todo o experimento. A solução resultante apresentava $20 \mathrm{mg} / \mathrm{ml}$, sendo filtrada em membrana esterilizante de $0,22 \mu$, MILLIPORE $^{\circledR}$, e conservada em temperatura de $4^{\circ} \mathrm{C}$.

\subsubsection{Formamida}

Utilizou-se Formamida, MERCK ${ }^{\circledR}$ artigo 9684.1000 para extração do azul de Evans das amostras corneanas.

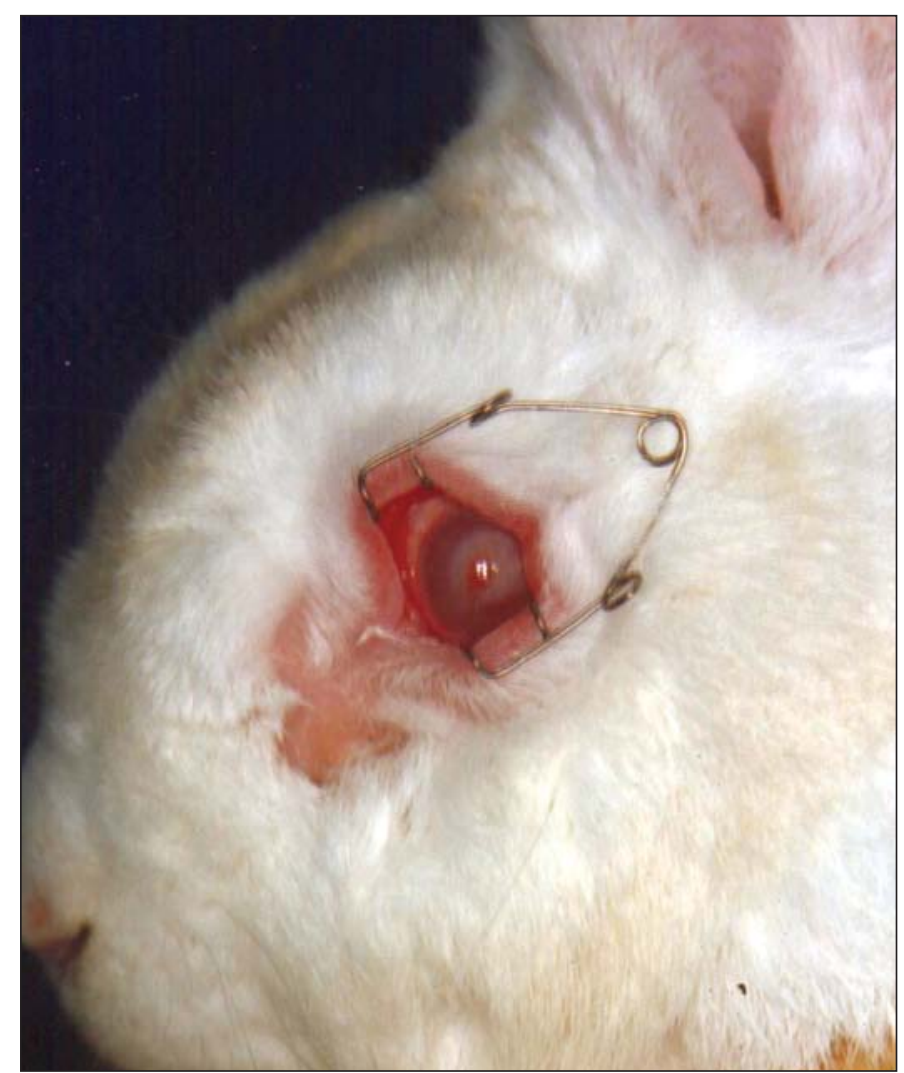

Figura 1 - Córnea após 5 dias de queimadura por $\mathrm{NaOH}$

\subsection{Inoculação do azul de Evans}

Inoculou-se o azul de Evans em todos os animais dos grupos I, II e III. Os coelhos, sob ação anestésica do éter inalatório, foram submetidos à injeção de azul de Evans na dose de $20 \mathrm{mg} / \mathrm{kg}$ de peso, segundo o método usado por Bordón de Corvalán em 1994. A inoculação foi realizada com agulha $13 \times 4,5 \mathrm{~mm}$ na veia marginal da orelha direita.

\subsection{Eutanásia}

Nos animais do grupo I, o sacrifício ocorreu 8, 10, 12, 14 e 16 horas após injeção do corante. Nos demais grupos, o sacrifício e a coleta das amostras ocorreram 10 horas após a inoculação.

Após anestesia inalatória com éter sulfúrico, todos os animais foram sacrificados com injeção letal endovenosa de 20 $\mathrm{ml}$ de ar, inoculado via veia marginal da orelha esquerda.

\subsection{Coleta das amostras}

Após colocação do blefarostato, procedeu-se a peritomia $360^{\circ}$ da conjuntiva. A seguir, as córneas foram extraídas com 1 $\mathrm{mm}$ de margem escleral em todos os animais. No grupo II, depois de retirada das córneas, as mesmas foram trepanadas centralmente com trépanos de 6,8 e $10 \mathrm{~mm}$.

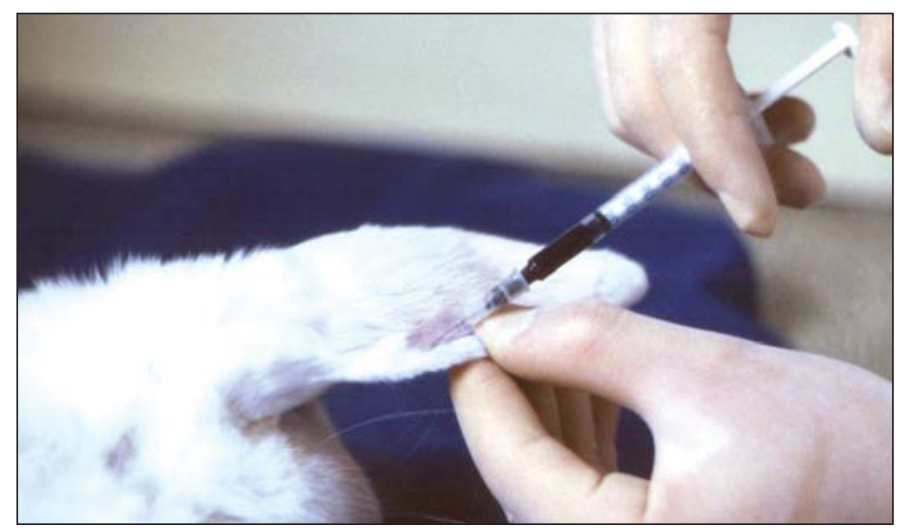

Figura 2 - Demonstração da inoculação endovenosa do Azul de Evans em veia marginal da orelha direita

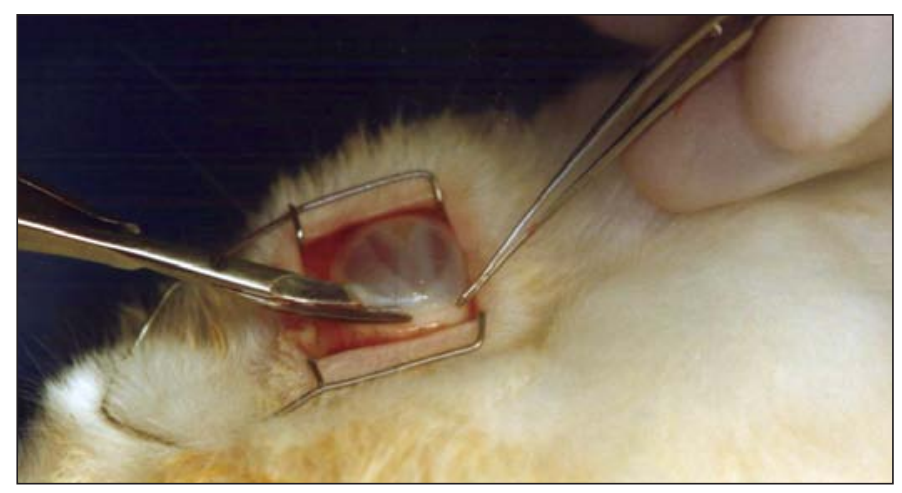

Figura 3 - Retirada da cornea com $1 \mathrm{~mm}$ de margem escleral para posterior quantificação do Azul de Evans 


\subsection{Extração do corante}

Após a retirada da córnea margeada por $1 \mathrm{~mm}$ de esclera, a amostra foi pesada em balança eletrônica HELMAC ${ }^{\circledR} \mathrm{e}$ imersa em Formamida Merck artigo 9684.1000 na proporção de $4 \mathrm{ml} / \mathrm{g}$. Esta solução foi deixada por 24 horas a $22^{\circ} \mathrm{C}$. Após, os tubos foram agitados mecanicamente por 15 segundos em agitador PHOENIX $^{\circledR}$ modelo AT 56. Finalmente, o corante extraído pela formamida foi conservado à temperatura constante de $-20^{\circ} \mathrm{C}$ para posterior leitura espectrofotométrica. Este procedimento foi realizado igualmente nos três grupos.

\subsection{Determinação espectrofotométrica do azul de Evans no tecido corneano}

Colocou-se $150 \mu 1$ de cada amostra corneana de formamida com o corante azul de Evans com auxílio de uma pipeta automática GILSON ${ }^{\circledR}$ em cada orifício da placa de Terazaki CORNING ${ }^{\circledR} \mathrm{e}$ realizou-se aferição espectrofotométrica em leitor de ELISA (BIOTEK) com filtro de $650 \mathrm{~nm}$ de comprimento de onda. Foi utilizada solução de formamida como branco para o teste.

As leituras foram interpoladas por regressão linear em uma curva padrão do corante. As concentrações das amostras foram calculadas em microgramas por mililitro e microgramas por miligrama de tecido corneano. Da mesma forma, esta determinação foi realizada igualmente em todos os grupos.

\section{Avaliação estatística}

\subsection{Análise de regressão linear e correlação}

Para a validação dos resultados espectrofotométricos das amostras corneanas frente às respectivas curvas padrões de calibração, empregou-se a análise de correlação para obtenção dos coeficientes de correlação (r) (BOX, HUNTER e HUNTER, 1978).

\subsection{Análise da variância}

Os resultados das aferições do azul de Evans corneano foram submetidos ao "Tukey-Kramer Multiple Comparisons Test" onde o valor $\mathrm{p}<0,05$ foi considerado significativo.

\subsection{Cálculo de média e desvio padrão}

Realizados através de calculadora Casio ${ }^{\circledR}$ F705-PX.

\section{RESULTADOS}

A concentração do azul de Evans na córnea dos animais do grupo I foi maior naqueles sacrificados 10 horas após a inoculação do corante com média de 15,28 $\pm 0,09 \mu \mathrm{g} / \mathrm{mg}$ de tecido.

A média da concentração do azul de Evans nas córneas dos animais sacrificados após 8 horas da inoculação foi de $15,28 \pm 0,73 \mu \mathrm{g} / \mathrm{mg}$ de tecido. $O$ desvio padrão da concentração do corante foi maior às 8 horas do que às 10 horas depois da injeção endovenosa.
A concentração média às 12 horas pós-inoculação foi de $14,92 \pm 036 \mu \mathrm{g} / \mathrm{mg}$ de tecido. Às $14 \mathrm{e} 16$ horas depois da injeção endovenosa as médias encontradas corresponderam a $13,36 \pm 0,92 \mu \mathrm{g} / \mathrm{mg}$ e $14,76 \pm 0,18 \mu \mathrm{g} / \mathrm{mg}$ de tecido respectivamente (Gráfico 1).

Nos animais do grupo II, encontrou-se maior concentração do corante nos $10 \mathrm{~mm}$ centrais da córnea com média de $1,32 \pm$ $0,05 \mu \mathrm{g} / \mathrm{mg}$ de tecido. Nos $6 \mathrm{~mm}$ e $8 \mathrm{~mm}$ centrais da córnea as concentrações médias do azul de Evans corresponderam a $0,93 \pm 0,01 \mu \mathrm{g} / \mathrm{mg}$ e $1,20 \pm 0,06 \mu \mathrm{g} / \mathrm{mg}$ de tecido respectivamente (Gráfico 2).

Nas córneas dos olhos do lado direito dos animais do grupo III, as quais foram submetidas à queimadura química, houve concentração do azul de Evans com média de 23,74 \pm $2,64 \mu \mathrm{g} / \mathrm{mg}$ de tecido. Nas córneas dos olhos contralaterais dos mesmos animais (olho controle) a concentração do corante atingiu a média de $16,71 \pm 2,04 \mu \mathrm{g} / \mathrm{mg}$ de tecido (Gráfico 3 ).

\section{DISCUSSÃO}

\section{Grupo I}

O estudo propôs, através dos animais do grupo I, mensurar espectrofotometricamente o azul de Evans na córnea e encontrar o período de tempo de maior concentração deste corante no tecido. Quantificou-se o azul de Evans a partir das primeiras 8 horas após inoculação endovenosa do corante. Repetiu-se o procedimento a cada 2 horas até as 16 horas pósinoculação. Constatou-se que, em todos estes horários estudados ( $8 \mathrm{~h}, 10 \mathrm{~h}, 12 \mathrm{~h}, 14 \mathrm{~h}, 16 \mathrm{~h})$, pode-se encontrar e mensurar o corante no tecido. Após 10 horas de injeção do corante relatou-se concentração média de 15,28 $\pm 0,09 \mu \mathrm{g} / \mathrm{mg}$ de tecido. Concluiu-se que, neste período de tempo, houve maior concentração do corante (com menor desvio padrão) no tecido

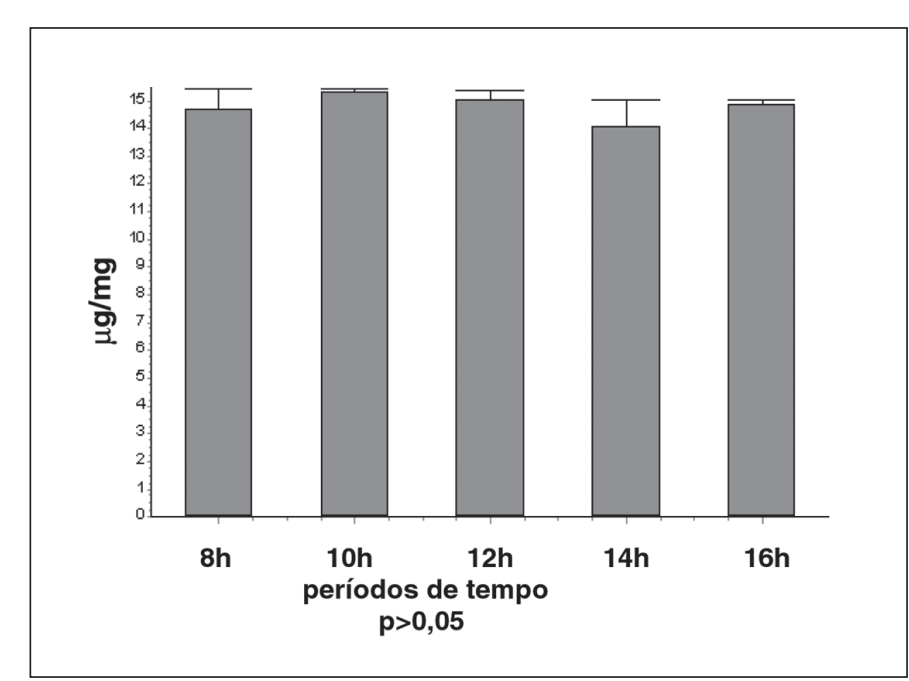

Gráfico 1 - Apresentação das médias com desvio padrão das concentrações do azul de Evans em $\mu \mathrm{g} / \mathrm{mg}$ de tecido nos períodos de tempo estudados (8, 10, 1214 e 16 horas) (Grupo I) 


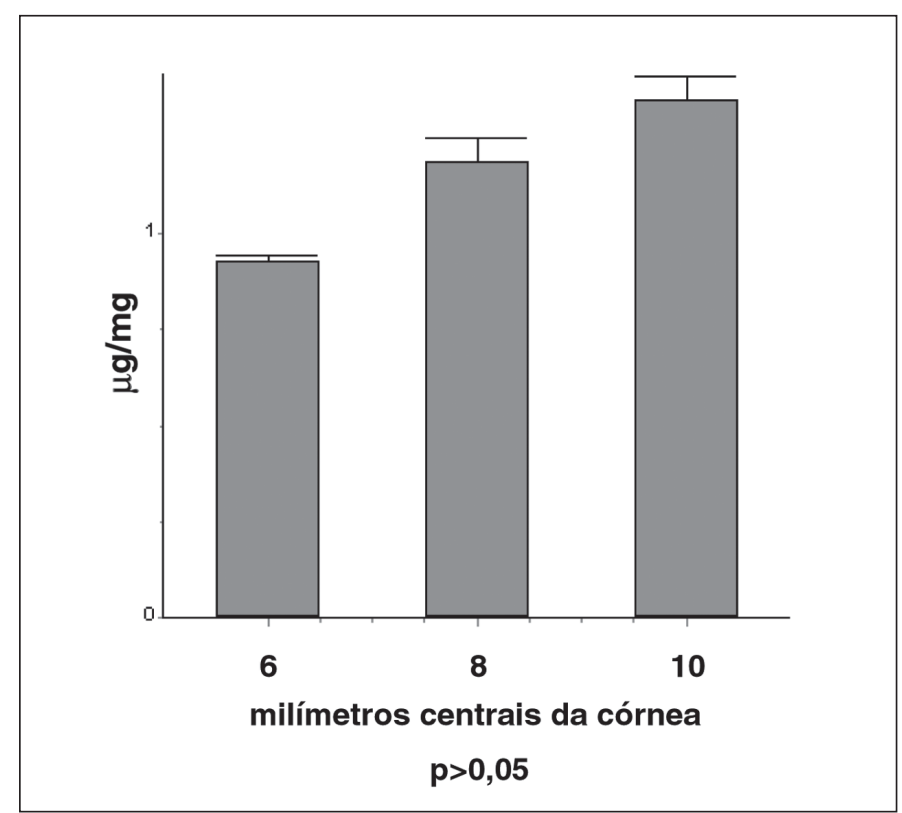

Gráfico 2 - Resultado das concentrações médias com desvio padrão de azul de Evans $(\mathrm{em} \mu \mathrm{g} / \mathrm{mg})$ nas córneas dos animais do grupo II

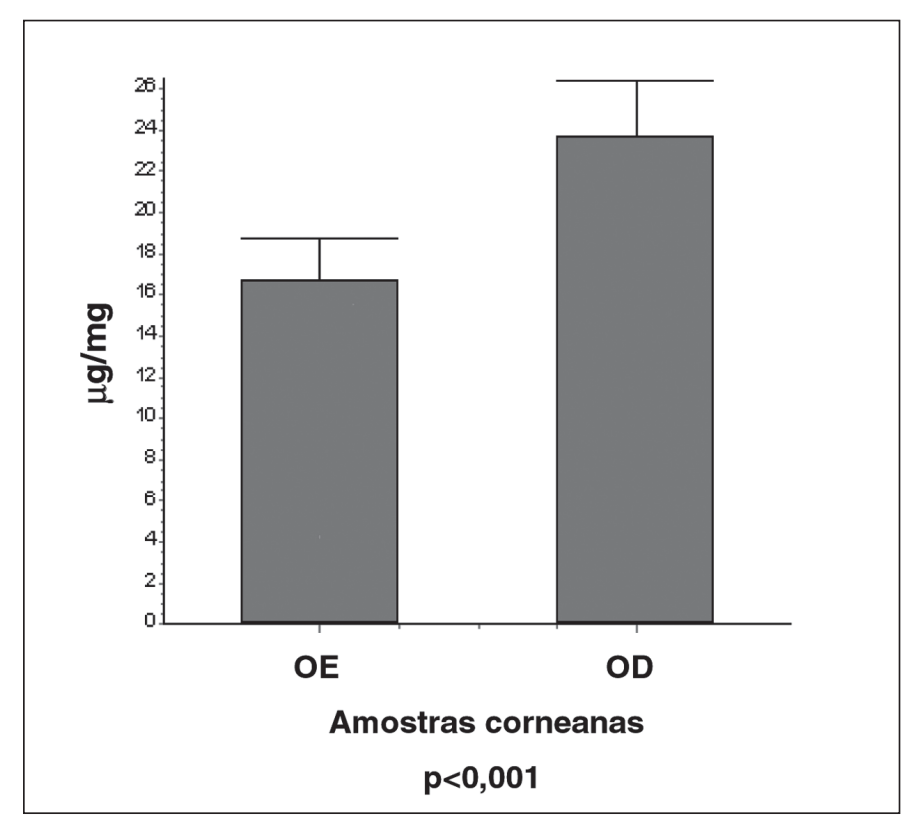

Gráfico 3 - Apresentação das concentrações médias com desvio padrão de azul de Evans (em $\mu \mathrm{g} / \mathrm{mg}$ ) nas córneas dos animais do grupo III

corneano. A média da concentração após 8 horas de inoculação do corante foi semelhante à média das 10 horas, porém o desvio padrão foi maior no primeiro período de tempo. Portanto, considerou-se o período de 10 horas após inoculação endovenosa como sendo o período de tempo de maior tingimento do azul de Evans na córnea.

As diferenças das médias das concentrações do corante no grupo I não foram estatisticamente significativas entre os horários estudados $(\mathrm{p}>0,05)$.

\section{Grupo II}

A córnea consiste num tecido avascular que tem sua nutrição baseada principalmente nos vasos sangüíneos do limbo, humor aquoso e lágrimas ${ }^{(38)}$. Há uma considerável diferença entre a córnea periférica, próxima ao limbo, e a área central. A mais importante é a presença de vasos no limbo nutrindo o estroma corneano periférico ${ }^{(39)}$. As paliçadas de Vogt (elevações fibrovasculares radiais) permitem o aporte sangüíneo bem próximo ao estroma corneano periférico ${ }^{(40)}$.

No grupo II desta pesquisa, comprovou-se a distribuição centrípeta do azul de Evans na córnea. Os valores encontrados nos fragmentos trepanados contendo os $6 \mathrm{~mm}$ centrais da córnea foram menores que aqueles encontrados nos fragmentos corneanos com $8 \mathrm{~mm}$ de diâmetro. Da mesma forma, as concentrações em $\mu \mathrm{g} / \mathrm{mg}$ de azul de Evans mensuradas nos $8 \mathrm{~mm}$ centrais da córnea foram menores do que aquelas encontradas nos $10 \mathrm{~mm}$ centrais do tecido. A diferença entre os subgrupos deste grupo II não demonstrou ser estatisticamente significante ( $p>0,05)$. No entanto, quando se compara a concentração do azul de Evans nos animais controle do grupo III, onde houve retirada da córnea margeada de $1 \mathrm{~mm}$ de esclera, com qualquer um dos subgrupos do grupo II (córneas trepanadas) observouse diferença estatística $(\mathrm{p}<0,001)$. Este fato demonstra que a proximidade do estroma corneano com os vasos do limbo está diretamente ligada à maior concentração do corante e acúmulo de proteínas plasmáticas no local. Quanto mais longe dos vasos límbicos, ou seja, quanto mais próximo ao centro da córnea, menor a concentração do corante no tecido.

\section{Grupo III}

A queimadura corneana por álcali produz graves lesões na estrutura ocular. Além do epitélio corneano, o álcali penetra no estroma, atinge o endotélio e chega a estruturas do segmento anterior do olho como íris, cristalino e corpo ciliar. Os agentes alcalinos que mais promovem dano ocular são: amônia, cal, soda cáustica e hidróxido de potássio( ${ }^{(36)}$.

Optou-se pela queimadura corneana com soda cáustica a 1 $\mathrm{N}$ devido ao fato deste modelo de trauma apresentar-se como causador de lesão grave às estruturas oculares, principalmente incitando uma rápida resposta inflamatória na córnea e limbo ${ }^{(36)}$.

$\mathrm{O}$ hidróxido de sódio $(\mathrm{NaOH})$ promove defeito epitelial persistente, úlcera trófica, neovascularização, necrose e até perfuração corneana ${ }^{(41)}$. Inicialmente o ânion hidróxido $(\mathrm{OH})$ saponifica os ácidos gordurosos das membranas celulares resultando na morte da célula. Os cátions reagem com os grupos carboxílicos $(\mathrm{COOH})$ do colágeno estromal e dos glicosaminoglicanos e a hidratação destes leva a perda da transparência da córnea ${ }^{(33)}$.

Imediatamente após a queimadura com hidróxido de sódio, observou-se edema importante e perda da transparência do tecido corneano. A córnea persistiu desepitelizada e o edema constante até o quinto dia após o procedimento da queimadura.

O epitélio conjuntival, composto de células germinativas no limbo, representa a fonte de células para a regeneração epitelial. 
Na queimadura por álcali há processo de "conjuntivalização" da superfície corneana ${ }^{(35)}$. Com a perda grande de células germinativas ocorre o pannus superficial para suprir a isquemia tecidual $^{(31)}$.

Ao quinto dia pós-queimadura, antes do sacrifício dos animais, as córneas dos olhos direitos já apresentavam processo de neovascularização superficial periférica com delgados vasos sangüíneos provenientes da região límbica.

A inflamação possui sinais característicos de calor, rubor, tumor, dor e perda da função. O calor e o rubor são resultados do aumento da microcirculação em torno da área lesada. Proteínas, células do plasma e líquido extravasado dos vasos sangüíneos ao tecido extravascular identificam o edema no processo inflamatório ${ }^{(42)}$.

Quando há queimadura corneana, imediatamente instala-se o edema e a hiperemia conjuntival pericorneana, como o observado no experimento.

A injúria tissular aguda causa alterações no fluxo vascular, no calibre dos vasos, na permeabilidade vascular e na exsudação leucocitária ${ }^{(8)}$. A queimadura induzida neste estudo teve por objetivo causar o processo inflamatório agudo para que as alterações da permeabilidade vascular pudessem ser mais bem avaliadas.

Em condições fisiológicas, não há passagem de proteínas plasmáticas dos capilares ao espaço intersticial. No entanto, na inflamação ocorre esta passagem, estimando-se como sendo de cinco a sete vezes maior do que num vaso normal ${ }^{(8)}$. Esta exsudação das proteínas causou, após injúria provocada nas córneas dos animais do grupo III, o edema persistente do tecido. Provavelmente, este edema foi mantido pelo aumento da permeabilidade vascular dos vasos perilímbicos. Neste trabalho, optou-se pela retirada de tecido corneano margeado por um milímetro de tecido escleral em função da presença de capilares límbicos que estão envolvidos nas alterações exsudativas relacionadas a reações inflamatórias.

Portanto, a formação do exsudato é causada pelo aumento da pressão hidrostática, pelo aumento do fluxo sangüíneo e pelas alterações na permeabilidade da parede vascular ${ }^{(18)}{ }^{\circ}$ incremento desta mudança no padrão vascular foi mensurado nesta pesquisa devido ao complexo que se formou entre o azul de Evans e a albumina.

A quantificação do fluxo transcapilar tecidual tem valor na avaliação da exsudação plasmática em vigência de reações inflamatórias, traumas ou infecções, pois são estas, causas incontestáveis de aumento da permeabilidade capilar ${ }^{(8)}$.

A revisão da literatura oferece métodos quantitativos para aferir alterações da permeabilidade capilar como a dosagem de catabólitos do ácido araquidônico ${ }^{(15-17)}$, sendo que, para esta finalidade, requer-se considerável implementação laboratorial. O método utilizado nos animais do grupo I deste estudo determina os valores de referência e o momento máximo do fluxo transcapilar do corante azul de Evans nas córneas.Poderá ser utilizado em outros modelos experimentais correlacionados, aos moldes de outros autores ${ }^{(11-12)}$.
O azul de Evans foi quantificado em diversos estudos para avaliação da permeabilidade vascular alterada. Após lesões inflamatórias de pele em coelhos, pelo método de colorimetria, autores constataram aumento da concentração do corante nestas lesões devido ao aumento da exsudação de proteínas plasmáticas ${ }^{(14)}$. Mediadores químicos da inflamação e injúrias com lesão vascular direta são exemplos de aumento do fluxo transcapilar. A quantidade de albumina que extravasa aos tecidos não é significativa em situações fisiológicas, mas o extravasamento é importante devido à alteração da permeabilidade capilar ${ }^{(8,11-12,43)}$. Portanto, o azul de Evans, combinado com a albumina, sofre deslocamento do espaço intravascular em direção ao extravascular e deposita-se no interstício do tecido, como foi constatado nesta pesquisa.

Autores revelam que a alteração da permeabilidade capilar pode ser de origem neurogênica, por exemplo, após estímulo vagal ${ }^{(44)}$. Também pode ocorrer após doses sistêmicas de histamina e endotoxina, demonstrando a origem hormonal da alteração vascular ${ }^{(14)}$. Além destas experiências, a literatura ainda relata pesquisas com nistatina, BCG e leucotrienos ${ }^{(10,13)}$. Em todos os experimentos, utilizou-se o azul de Evans para avaliar o processo de aumento da permeabilidade vascular.

Neste estudo, as córneas queimadas dos animais do grupo III demonstraram média de 23,74 $\pm 2,64 \mu \mathrm{g} / \mathrm{mg}$ de azul de Evans no tecido enquanto as córneas controle do mesmo grupo apresentaram média de 16,71 $\pm 2,04 \mu \mathrm{g} / \mathrm{mg}$. Este dado revela maior concentração do corante nas córneas que sofreram injúria tissular em relação às córneas controle do olho contralateral $(\mathrm{p}<0,001)$. Comparando-se os valores quantificados nas córneas controle do grupo III com os valores do grupo I (10 horas) observa-se que não há diferença significativa entre os mesmos ( $\mathrm{p}>0,05)$.

Observou-se, através da mensuração quantitativa do corante azul de Evans, que a córnea, ao ser submetida a processo inflamatório, sofre exsudação importante dos vasos perilímbicos.

Ressalta-se que, os estudos utilizando o azul de Evans são adequados para o nosso meio e que a quantificação do corante pode determinar a reação inflamatória corneana devido à alteração da permeabilidade vascular.

\section{CONCLUSÕES}

Verificou-se que o período de tempo de concentração máxima do azul de Evans na córnea foi de dez horas após inoculação endovenosa em coelhos.

Determinou-se que as concentrações do azul de Evans são maiores na região límbica do que no centro da córnea de coelhos, resultando no mecanismo de distribuição centrípeta do corante.

As concentrações do azul de Evans teciduais, quantificadas pelo micrométodo espectrofotométrico, demonstraram haver aumento da permeabilidade vascular nas córneas de coelhos submetidas à queimadura química. 


\section{ABSTRACT}

Purpose: To detect Evans blue in the normal cornea, attempting to determine the period of maximum concentration of the dye after intravenous injection and to study vascular permeability in an animal model of corneal inflammation induced by alkali burn, after Evans blue injection. Methods: Fifty rabbits were divided into 3 groups. Group I (25 animals): $20 \mathrm{mg} / \mathrm{kg}$ Evans blue were injected and the animals were sacrificed after 8,10 , 12, 14 and 16 hours. The corneas were removed and the dye concentration was measured by a spectrophotometric micromethod. Group II: in 15 animals, 10 hours after injection, the corneas were centrally fragmented with number 6,8 and $10 \mathrm{~mm}$ trephines. Evans blue was extracted the same way as in Group I. Group III: alkali burn was induced in the cornea of the right eyes of 10 animals, using $1 \mathrm{~N} \mathrm{NaOH}$. Five days after the procedure, the animals were sacrificed. Ten hours prior to sacrifice, Evans blue was injected. The left corneas were the control. Results: In group I, mean Evans blue concentration is at $10 \mathrm{~h}: 15.28 \pm 0.09 \mu \mathrm{g} / \mathrm{mg}$. In group II, mean Evans blue concentrations are: $6 \mathrm{~mm}: 0.93 \pm 0.01 \mu \mathrm{g} / \mathrm{mg} ; 8 \mathrm{~mm}: 1.20 \pm 0.06$ $\mu \mathrm{g} / \mathrm{mg} ; 10 \mathrm{~mm}: 1.32 \pm 0.05 \mu \mathrm{g} / \mathrm{mg}$. In group III, mean Evans blue concentrations are: right eyes (alkali burns): $23.74 \pm 2.64 \mu \mathrm{g} /$ mg and left eyes (control): $16.71 \pm 2.04 \mu \mathrm{g} / \mathrm{mg}$. Conclusions: This is the first time that Evans blue has been quantified in rabbit's cornea. It was possible to detect the dye from 8 to 16 hours after intravenous injection. We can conclude that Evans blue detection is a good method to quantify the alteration of vascular permeability in rabbit's cornea.

Keywords: Evans blue; Spectrophotometry; Permeability; Cornea; Rabbits.

\section{REFERÊNCIAS}

1. Linderkamp O, Mader T, Butenandt O, Riegel KP. Plasma volume estimation in severely ill infants and children using a simplified Evans blue method. Eur J Pediatr 1977;125:135-41.

2. Woods KL, Smith LJ, Graham DY. Intragastric accumulation of Evans blue dye as a method for assesing aspirin-induced acute gastric mucosal injury in humans. Dig Dis Sci 1988;33:769-73.

3. Freedman FB, Johnson J. Equilibrium and kinetic properties of the Evans blue-albumin system. Am J Physiol 1969;16:675-81.

4. Leveen HH, Fishman WH. Combination of Evans blue with plasma protein: its significance in capillary permeability studies, blood dye disappereance curves, and its use as a protein tag. Am J Physiol 1947;26:26-33.

5. Rawson RA. The binding of T-1824 and structurally related diazo dyes by the plasma proteins. Am J Physiol 1943;138:708-17.

6. Caster WO, Simon AB, Armstrong WD. Evans blue in tissues of the rat. Am J Physiol 1955;183:317-21.

7. Clausen DF, Lifson N. Determinations of Evans blue dye in blood and tissues. Proc Soc Exp Biol Med 1956;91:11-4.

8. Guyton AC. Tratado de fisiologia médica. 5.ed., Rio de Janeiro: Interamericana; 1976.

9. Steele RH, Wilhelm DL. The inflammatory reaction in chemical injury. Increased vascular permeability and erythema induced by various chemicals. Br J Exp Pathol 1966; 47:612-23.

10. Baccaro MR, Mariano M, Malucelli BE. Chronically inflammed tissue activates plasma mediators of vascular permeability [published erratum in Braz J Med Biol Res 1990;23:477]. Braz. J Med Biol Res 1990;23:179-85.

11. Bordón de Corbalán A. C. Aplicação do micrométodo espectrofotométrico para a determinação de azul de Evans em plasma e tecido colônico de ratos Wistar [dissertação]. Curitiba: Universidade Federal do Paraná; 1994.
12. Hajar N. O uso do azul de Evans para avaliar a permeabilidade vascular na colite induzida com ácido acético a 10\% em ratos Wistar [dissertação]. Curitiba, Universidade Federal do Paraná; 1994.

13. Obata T. Kobayashi T, Okada Y, Nakagawa N, Terawaki T, Aishita H. Effect of a peptide leukotriene antagonist Ono-1078 on antigen-induced airway microvascular leakage in actively sensitized Guinea pigs. Life Sci 1992;51:1577-83.

14. Ukada K, Takeuchi Y, Movat HZ. Simple method for quantitation of enhaced vascular permeability. Proc Soc Exp Biol Med 1970;133:1384-7

15. Sharon P, Stenson WF. Metabolism of arachidonic acid in acetic acid colitis in rats. Similary to human inflammatory bowel disease. Gastroenterology 1985;88(1 Pt 1):55-63.

16. Simmons PM, Salmon JA, Moncada S. The release of leukotriene B4 during experimental inflammation. Biochem Pharmacol 1983;32:1353-9.

17. Vilaseca J, Salas A, Guarner F, Rodriguez R, Malagelada JR. Participation of thromboxane and other eicosanoid synthesis in the course of experimental inflammatory colitis. Gastroenterology 1990;98:269-77.

18. Cotran RS, Suter ER, Majno G. The use of colloidal carbon as a tracer for vascular injury. Vasc Dis 1967;4:107-10.

19. Robbins SL, Cotran RS, Kumar V. Patologia estrutural e funcional. 4. Ed. Rio de Janeiro: Guanabara Koogan; 1991.

20. Brokaw JJ, White GW. Calcitonin gene-related peptide potentiates substance P-induced plasma extravasation in the rat trachea. Lung 1992;170:85-95.

21. Haas DA, Nakanishi O, MacMillan RE, Jordan RC, Hu JW. Development of an orofacial model of acute inflammation in the rat. Arch Oral Biol 1992;37:417-22.

22. Louis SM, Jamieson A, Russel NJW, Dockray GJ. The role of substance P and calcitonin gene-related peptide in neurogenic plasma extravasation and vasodilatation in the rat. Neuroscience 1989;32:581-6.

23. Lundberg JM, Saria A. Capsaicin-induced desensitization of airway mucosa to cigarette smoke, mechanical and chemical irritans. Nature 1983;302:251-3.

24. McMahon SB, Lewin GR, Anand P, Ghatel MA, Bloom SR. Quantitative analysis of peptide levels and neurogenic extravasation following regeneration of afferents to appropriate and inappropriate targets. Neuroscience 1989;33:67-73.

25. Reis ML, Okino L, Rocha e Silva M. Comparative pharmacological actions of bradykinin and related kinins of larger molecular weights. Biochem Pharmacol 1971;20:2935-46.

26. Rinkema LE, Bemis KG, Fleisch JH. Production and antagonism of cutaneous vascular permeability in the Guinea pig in response to histamine, leukotrienes and A23187. J Pharmacol Exp Ther 1984;230:550-7.

27. Rogers DF, Belvisi MG, Aursudkij B, EvansTW, Barnes P J. Effects and interactions of sensory neuropeptides on airway microvascular leakage in Guinea pigs. Br J Pharmacol 1988;95:1109-16.

28. Saria A, Lundeberg JM, Skofitsch G, Lembeck F. Vascular protein linkage in various tissues induced by substance $\mathrm{P}$, capsaicin, bradykinin, serotonin, histamine and by antigen challenge. Naunyn-Schmiedeberg's. Arch Pharmacol 1983;324:212-8.

29. Szabo S, Pihan G, Trier JS. Alterations in blood vessels during gastric injury and protection. Scand J Gastroenterol 1986;21(Suppl 125):92-9.

30. Brown SI, Wasserman HE, Dun MW. Alcaki burns of the cornea. Arch Ophthalmol 1969;82:91-4.

31. Geggel HS, Thoft RA, Friend J. Histology of human conjunctival transplantation. Cornea 1984;3:11-5.

32. Johnson-Wint B. Autocrine regulation of collagenase production by passaged corneal stromal cells in vivo [abstract]. Invest Ophthalmol Vis Sci 1987;28(3 Suppl):230.

33. McCulley JP. The cornea: Scientific Foundation and Clinical Practice. 2.ed. Boston: Little, Brown; 1987.

34. Paterson CA, Pfister RR, Levinson RA. Aqueous humor $\mathrm{pH}$ changes after alkali burns. Am J Ophthalmol 1975;79:414-9.

35. Shapiro MS, Friend J, Thoft RA. Corneal re-epithelization from the conjunctiva. Invest Ophthalmol Vis Sci 1981;21:135-42.

36. Wagoner MD. Chemical injuries of the eye: current concepts in pathophysiology and therapy. Surv Ophthalmol 1997;41:275-313.

37. Green TP, Johnson DE, Marchessault RP, Gatto CW. Transvascular flux and tissue accrual of Evans blue: effects of endotoxin and histamine. J Lab Clin Med 1988;11:173-83.

38. Zieske JD. Perpetuation of stem cells in the eye. Eye 1994;8(Pt 2):163-9.

39. Yanoff M, Fine BS. Atlas of ocular pathology. Saint Louis: C.V. Mosby; 1996.

40. Dua HS, Gomes JAP, Singh A. Corneal epithelial wound healing. Br J Ophthalmol 1994;78:401-8.

41. Thoft RA, Friend J. The X, Y, Z, hypothesis of corneal epithelial maintenence. Invest Ophthalmol Vis Sci 1983;24:1442-3.

42. Wilhelm DL. Patologia. 7.ed. Rio de Janeiro: Guanabara Koogan; 1982.

43. Bernauer W. Effects of glucocorticosteroids in rats with acute myocardial infarction. Arch Int Pharmacodyn Ther 1980;244:86-99.

44. Lundberg JM, Saria A. Capsaicin-sensitive vagal neurons involved in control of vascular permeability in rat trachea. Acta Physiol Scand 1982;115:521-3. 